\title{
Chemical Lesion of the Bed Nucleus of the Stria Terminalis Blocks the Behavioral Consequences of Uncontrollable Stress
}

\author{
Sayamwong E. Hammack \\ Emory University School of Medicine
}

\author{
Kristen J. Richey, Linda R. Watkins, and \\ Steven F. Maier \\ University of Colorado
}

\begin{abstract}
Uncontrollable or inescapable shock (IS) produces behavioral changes that are characterized by a sensitized fear system and a deficit in fight-flight responding. These behavioral changes have been argued to represent an anxiety-like state produced by the uncontrollability of the stressor. The bed nucleus of the stria terminalis (BNST) has been implicated in the mediation of long-duration responses to unpredictable stressors, which have also been argued to represent anxiety. In the present study, the effects of BNST chemical lesion on the IS-induced sensitization of freezing to an environment previously paired with shock and the IS-induced impairment of escape responding were investigated. BNST chemical lesion blocked the potentiation of freezing and the increases in escape latency that normally

follow IS.
\end{abstract}

The bed nucleus of the stria terminalis (BNST) is adjacent to the anterior commissure in the basal forebrain and makes up the rostral part of the continuum known as the extended amygdala. The BNST has been strongly implicated in mediating the responses to stimuli that contain an affective salience, so that (a) BNST activation produces neuroendocrine (Dunn, 1987) and behavioral (Casada \& Dafny, 1991) responses that resemble those produced by stress, and (b) BNST inactivation decreases the neuroendocrine and behavioral responses to stress (Gray et al., 1993), and blocks some forms of unconditioned fear (Davis, Walker, \& Lee, 1997; Fendt, Endres, \& Apfelbach, 2003; Walker \& Davis, 1997) and the effects of centrally injected corticotropin-releasing hormone (CRH; Lee \& Davis, 1997). Furthermore, stressors increase BNST levels of stress-related neurotransmitters and neuropeptides, including CRH (Chappell et al., 1986; Makino et al., 1999; Stout, Mortas, Owens, Nemeroff, \& Moreau, 2000) and norepinephrine (NE; Pacak, McCarty, Palkovits, Kopin, \& Goldstein, 1995). In addition, the release of these substances within the BNST has been shown to mediate, in part, some of the behavioral consequences of stressor exposure (Cecchi, Khoshbouei, Javors, \& Morilak, 2002; Lee \& Davis, 1997).

Although the BNST mediates many responses to stressors, its function is not always critical (Gewirtz, McNish, \& Davis, 1998;

Sayamwong E. Hammack, Department of Psychiatry, Emory University School of Medicine; Kristen J. Richey, Linda R. Watkins, and Steven F. Maier, Department of Psychology and Center for Neuroscience, University of Colorado.

This work was supported by National Institutes of Health Grant MH50479 and by the Undergraduate Research Opportunities Program at the University of Colorado.

Correspondence concerning this article should be addressed to Sayamwong E. Hammack, Department of Psychiatry, Emory University School of Medicine, 1639 Pierce Drive, Suite 4000, Atlanta, GA 30322. E-mail: shammac@emory.edu
Hitchcock \& Davis, 1991; LeDoux, Iwata, Cicchetti, \& Reis, 1988 Treit, Aujla, \& Menard, 1998). A consideration of the circumstances in which the BNST is, or is not, involved in the mediation of the consequences of stressor exposure has led Davis and colleagues to suggest that the BNST mediates long-duration responses to unpredictable threatening or aversive stimuli, while the anatomically related central nucleus of the amygdala $(\mathrm{CeA}) \mathrm{me}-$ diates short-term responses to stimuli that are predictable in nature (Walker \& Davis, 1997; Walker, Toufexis, \& Davis, 2003). Davis and colleagues called these long-duration, BNST-mediated responses "anxiety," and the short-duration, CeA-mediated responses "fear."

Exposure to uncontrollable or inescapable shock (IS) produces a constellation of behavioral changes that are not observed if the shock is controllable or escapable (ES). These behavioral responses have been called "learned helplessness" (Maier \& Seligman, 1976, p. 3) or "behavioral depression" (Weiss et al., 1981, p. 167 ) and include a sensitization in behaviors related to fear and anxiety and a concomitant decrease in behaviors related to fightflight. Uncontrollable shock is by nature unpredictable, and the behavioral changes in fear and anxiety are long lasting (24-48 hr), so that this behavioral paradigm produces a state that meets the Davis group's criteria for "anxiety." Hence, the behavioral changes observed following uncontrollable shock might be expected to be blocked by BNST inactivation, but not CeA inactivation. It is already known that large lesions of the amygdala that include the CeA do not block the usual behavioral consequences of IS (Maier et al., 1993). In the present study, the effects of chemical lesions of the BNST on IS-induced changes in fear and escape were investigated.

\section{Method}

\section{Subjects}

Male Sprague-Dawley rats (Harlan Labs, Madison, WI) weighing 275$325 \mathrm{~g}$ were used in all experiments. Rats were single-housed and main- 
tained on a 12-hr light-dark cycle. Food and water were provided ad libitum. Behavioral testing was performed between 0800-1200, during the light portion of the light cycle. All procedures were approved by the Institutional Animal Care and Use Committee of the University of Colorado at Boulder.

\section{Apparatus}

Rats given IS were placed into Plexiglas tubes $17.5 \mathrm{~cm}$ long $\times 7.0 \mathrm{~cm}$ wide. Each rat's tail extended from the rear of the tube and was attached with tape to a Plexiglas rod. Electrodes were fixed to the tail, and computer-controlled 1.0-mA shocks were created by shock sources modeled after the Grason-Stadler Model 700 shock source.

For behavioral testing rats were placed into shuttleboxes measuring 46.0 $\mathrm{cm}$ long $\times 20.7 \mathrm{~cm}$ wide $\times 20 \mathrm{~cm}$ high. Scrambled $0.5-\mathrm{mA}$ footshocks were delivered through stainless steel grids on the floor of the apparatus. The shuttle box was divided into two halves by an aluminum wall containing an archway that allowed passage from one side to the other.

\section{Procedure}

Rats were anesthetized with Halothane, and a 10- $\mu$ l syringe attached to an infusion pump was stereotaxically placed into the region of the BNST. Coordinates for BNST infusion, taken from the atlas of Paxinos and Watson (1998), were, from bregma, AP $=-0.4 \mathrm{~mm}, \mathrm{DV}=-6.8 \mathrm{~mm}$, and $\mathrm{ML} \pm 1.7 \mathrm{~mm}$. Two hundred nanoliters of $N$-methyl-D-aspartate (NMDA; Sigma-Aldrich, St. Louis, MO) was infused into each BNST over 4 min. The tip of the injector was located in the lateral BNST near the junction of the dorsal and ventral aspects of the BNST. For sham-operated control animals, equivolume saline was infused.

One week after surgery, rats were assigned to one of four groups: IS + lesion, IS + sham, home-cage + lesion, or home-cage + sham. Rats in the IS groups were given 100 five-s tailshocks delivered on a 1-min variableinterval schedule. Home-cage rats received no treatment on the treatment day.

All subjects received behavioral testing $24 \mathrm{hr}$ later. Both conditioned fear and shuttle box escape learning were tested by means of a procedure described elsewhere (Maier et al., 1993). Freezing was measured for the first 5 min after placement in a shuttle box. Each subject's behavior was scored every $8 \mathrm{~s}$ as being either freezing or not freezing. Freezing was defined as the absence of all movement except that required for respiration. The observer was blind with regard to treatment condition, and interrater reliability has been calculated to be $>.92$.

This observation period was followed by two footshocks, which could be terminated by crossing to the other side of the shuttle box (fixed ratio-1 [FR-1] trials). IS does not alter FR-1 shuttle box escape latencies (Maier et al., 1993), therefore IS and home-cage subjects were exposed to shocks of equal duration. These two shocks were followed by a 20-min observation period in which freezing was scored. Prior work has indicated that this freezing is a measure of fear that has been conditioned to the contextual cue of the shuttle box (Fanselow \& Lester, 1988). This observation period was followed by three further FR-1 escape trials and then 25 FR-2 escape trials. The subjects were required to cross to the other side and then back to terminate shock on the FR-2 trials, and it is here that IS-induced escape deficits are typically revealed. Each shock terminated after $30 \mathrm{~s}$ if an escape response had not occurred.

\section{Histology}

At the completion of the study, rats were anesthetized, perfused, and their brains removed and fixed in a 10\% Formalin-30\% sucrose solution. Brains were then sectioned on a cryostat and stained with Cresyl violet. Lesion verification of the sections was conducted under a light microscope.

\section{Data Analysis}

Data were analyzed with repeated measures analysis of variance (ANOVA) and followed with Newman-Keuls analysis (alpha set at .05), which made all possible pairwise comparisons.

\section{Results}

A typical lesion is shown in Figure 1. NMDA lesions of the BNST blocked the effects of IS on later escape behavior and freezing behavior. FR-2 escape latencies are shown in Figure 2A. As is typical, exposure to IS led to poor escape performance in sham-lesioned rats, and this effect was eliminated by BNST lesion. The BNST lesion did not, by itself, alter escape performance. An ANOVA revealed a reliable effect of shock treatment, $F(1,27)=$ 5.482, $p<.05$; lesion, $F(1,27)=5.152, p<.05$; and an interaction between shock treatment and lesion, $F(1,27)=8.884$, $p<.05$. There were reliable interactions between trials and shock treatment, $F(4,108)=6.034, p<.05$; and trials and lesion treatment, $F(4,108)=5.133, p<.05$; but not between trials shock treatment, and lesion, $F(4,108)=1.742, p>.05$. A Newman-Keuls analysis revealed a reliable difference between rats in the IS + sham group and all other groups. No other group differences were found.

The same pattern was present with regard to conditioned fear (Figure 2B). For freezing behavior, ANOVA revealed a reliable effect of shock treatment, $F(1,26)=17.369, p<.05$, and lesion, $F(1,26)=5.046, p<.05$. The interaction between shock treatment and lesion was not quite significant, $F(1,26)=1.904, p>$ .05. There was a reliable interaction between 2-min blocks of freezing and shock treatment, $F(9,234)=4.001, p<.05$, but not between 2-min blocks of freezing and lesion, $F(9,234)=1.210$, $p>.05$. There was no interaction between 2-min blocks of freezing, shock treatment, and lesion, $F(9,234)=1.036, p>.05$.

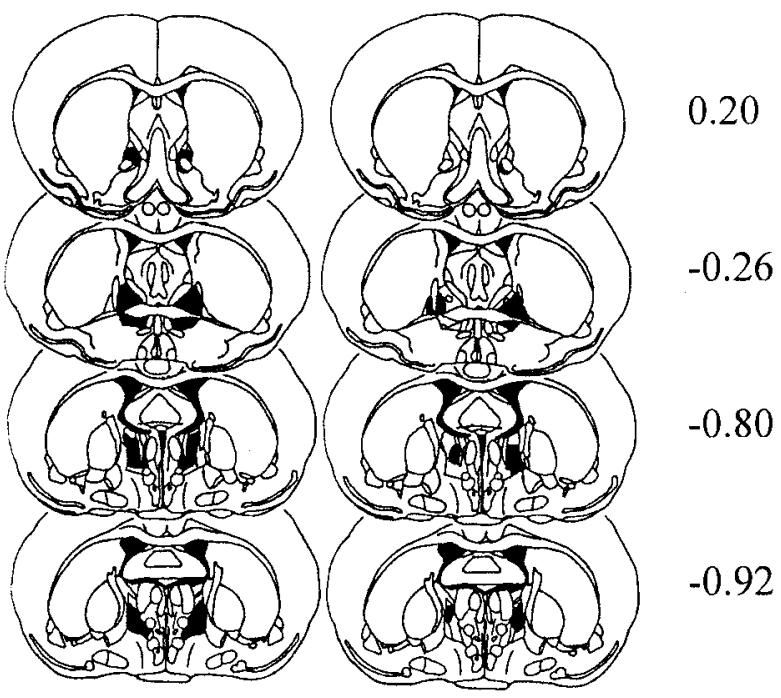

Figure 1. The largest (left) and smallest (right) bed nucleus of the stria terminalis lesions for which data were included. Coordinates are reported from bregma. Reprinted from The Rat Brain in Stereotaxic Coordinates, 4th ed., G. Paxinos and C. Watson, Figures 17, 19, 21, and 22, Copyright 1998, with permission from Elsevier 
A

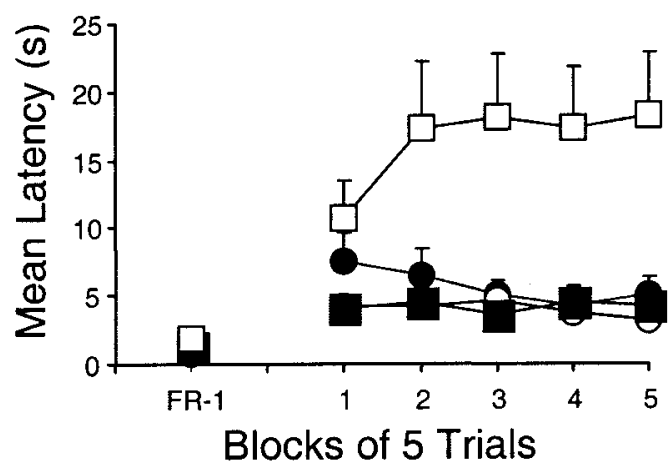

B

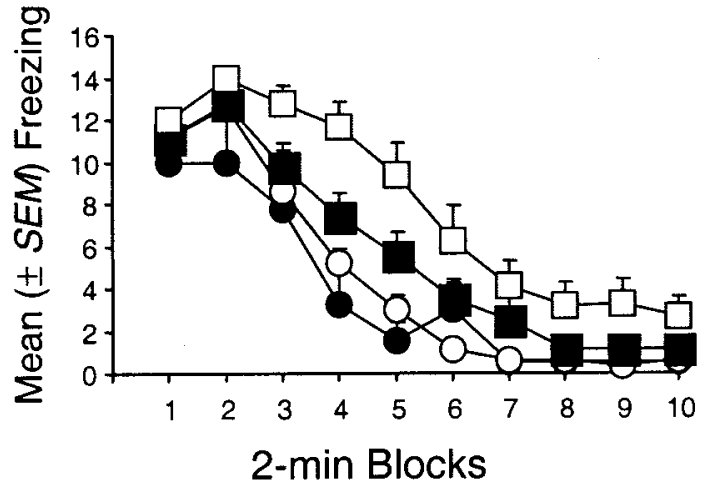

Figure 2. A: Mean ( $\pm S E M)$ shuttle box escape latencies for fixed-ratio 1 (FR-1) trials and five blocks of FR-2 trials. Rats either received inescapable shock (IS) or were left in their home cages $24 \mathrm{hr}$ earlier. One week before shock treatment, rats were either chemically lesioned in the bed nucleus of the stria terminalis or were given sham surgery. B: In the same rats, mean $( \pm S E M)$ number of 8 -s periods in which freezing occurred across 2-min blocks, after two shocks in the shuttle box. Open circles represent home cage/sham; closed circles, home cage/lesion; open squares, IS/sham; and closed squares, IS/lesion. In both panels, some SEMs are too small for error bars to be visible.

A Newman-Keuls analysis revealed a reliable difference between the IS + sham group and all other groups. No other group differences were found.

\section{Discussion}

Chemical lesion of the BNST blocked the interference with escape responding and potentiated fear conditioning normally observed $24 \mathrm{hr}$ after IS. The lesions in this study spared the fibers of passage, thereby implicating BNST cell bodies in mediating these effects.

The BNST can be subdivided on the basis of its inputs and outputs (Dong, Petrovich, \& Swanson, 2001; Dong, Petrovich, Watts, \& Swanson, 2001; McDonald, Shammah-Lagnado, Shi, \& Davis, 1999), and BNST subregion can be functionally distinct and relevant (Cecchi et al., 2002). This preliminary report did not determine the BNST subregion mediating the behavioral consequences of uncontrollable shock; however, the data clearly show that at least one subregion of BNST neurons is critical.

Many studies have implicated the BNST in mediating the response to fearful or threatening stimuli (Davis et al., 1997; Fendt et al., 2003; Walker \& Davis, 1997), whereas many others have not
(Gewirtz et al., 1998; Hitchcock \& Davis, 1991; LeDoux et al., 1988; Treit et al., 1998). Davis and colleagues (Walker \& Davis, 1997; Walker et al., 2003) have suggested that this discrepancy is due to the nature of the stressor, and that long-duration responses to unpredictable stimuli (anxiety) are neuroanatomically distinct from shorter responses to predictable stimuli (fear). The former are mediated by activation of the BNST; and the latter, activation of the CeA. A similar distinction between fear (short-duration response to predictable stimuli) and anxiety (long-duration response to unpredictable stimuli) has been made with regards to uncontrollable stressors (Maier \& Watkins, 1998). Uncontrollable stressors have been argued to induce anxiety, and it has been further argued that this anxiety produces many of the behavioral responses of uncontrollable stress. Thus, the finding that BNST lesions block the behavioral changes of IS provides a parallel to the work of Walker et al. (2003) that used the startle paradigm.

However, Schulz and Canbeyli (2000) have reported that BNST lesions enhanced escape deficits in a different model of uncontrollability: learned despair. In this model, rats that have been exposed to forced swimming show decreased attempts to escape the same situation upon reexposure $24 \mathrm{hr}$ later. The difference between the Schulz and Canbeyli study and the results reported here could be explained by important methodological factors. First, Schulz and Canbeyli used electrolytic BNST lesions, which would destroy the fibers of the stria terminalis. These fibers carry projections from the $\mathrm{CeA}$ and basolateral and basomedial nuclei of the amygdala, which project to many areas, including several hypothalamic regions (MacLean, 1985). Second, the escape deficits reported here are produced by IS, but not by equivalent ES (Maier, 1990), suggesting that these behaviors result from stressor uncontrollability, and not other aspects of stressor exposure. Although learned despair may be an important model of depression, it is not clear what aspect of forced swim produces the escape deficits $24 \mathrm{hr}$ later, and Schulz and Canbeyli did not observe many escape failures $24 \mathrm{hr}$ after forced swim in nonlesioned rats (Schulz \& Canbeyli, 2000). Furthermore, the escape deficits in the present study were observed in a novel environment, ensuring that environmental cues did not mediate transfer from Day 1 stressor exposure, a possible conditioned effect. Schulz and Canbeyli have previously reported that BNST lesion reduces freezing behavior to uncontrollable aversive tones (Schulz \& Canbeyli, 1999), which is consistent with the effects of BNST lesion on freezing behavior reported here. In any case, learned helplessness and behavioral despair are not the same phenomenon, as one does not predispose rats to the other (Drugan, Skolnick, Paul, \& Crawley, 1989).

Similarly, Henke (1984) showed that electrolytic BNST lesion reduces escape deficits to a tone that had previously been paired with immobilization. Again, this effect may have been caused by destruction of the stria terminalis fibers rather than BNST cell bodies. By itself, BNST lesion did not affect escape behavior in control rats in the present study.

Shumake, Edwards, and Gonzalez-Lima (2002) found that basal oxidative metabolism was decreased in the BNST of rats bred for their susceptibility to the development of learned helplessness. However the BNST response of these rats to stressors was not tested, nor was the decreased oxidative metabolism correlated with behavioral activity. Although these data imply a role for the BNST in congenitally helpless rats, it is unclear how the BNST would respond to uncontrollable stress. 
IS has been associated with over-reactivity of NE in the locus coeruleus (LC; Weiss \& Simson, 1985) and serotonin (5-HT) in the caudal dorsal raphe nucleus (DRN; Grahn, Will, et al., 1999; Maswood, Barter, Watkins, \& Maier, 1998). If the BNST has a role in mediating the effects of IS, it would likely involve interactions with one or both of these systems. Weiss and colleagues have argued that IS, relative to ES, increases NE release within the $\mathrm{LC}$ and its projection regions, and that this increased NE downregulates LC $\alpha 2$ adrenergic autoreceptors so that cells in this region respond to subsequent stimulation with a potentiated release of NE (Weiss \& Simson, 1985). NE neurons in the LC are modulated by CRH (Casada \& Dafny, 1993), and the BNST is a rich extrahypothalamic source of CRH (Gray \& Magnuson, 1992; Moga, Saper, \& Gray, 1989; Phelix \& Paull, 1990; Shimada et al., 1989; Swanson, Sawchenko, Rivier, \& Vale, 1983). However, for at least one stressor, this regulation involves a $\mathrm{CRH}$ projection from the CeA, and not the BNST (Curtis, Bello, Connolly, \& Valentino, 2002). Fibers from the BNST do directly contact NE dendrites that extend into rostral dorsolateral peri-coerulear areas (Van Bockstaele, Peoples, \& Valentino, 1999), so that a BNST influence on the LC in some circumstances cannot be discounted. In addition to the possibility that the BNST is afferent to the LC, the LC may also modulate BNST activity. An extensive role has been found for NE release within the BNST in mediating the response to stressors (Cecchi et al., 2002; Onaka \& Yagi, 1998) and stress-induced drug reinstatement (Leri, Flores, Rodaros, \& Stewart, 2002). However, the source of BNST NE in this case appears to be the A1-A2 NE cell groups, with only a minor input from the LC (Aston-Jones, Delfs, Druhan, \& Zhu, 1999; Delfs, Zhu, Druhan, \& Aston-Jones, 2000).

We have argued that the DRN 5-HT system is also sensitized following IS. The neural activation marker, c-Fos, shows a greater expression in caudal DRN 5-HT neurons following IS, when compared with ES (Grahn, Will, et al., 1999), and prolonged elevated levels of 5-HT are observed following IS within the DRN (Maswood et al., 1998) and its projection regions (Amat, MatusAmat, Watkins, \& Maier, 1998a, 1998b; Bland et al., 2003). Moreover, pharmacological suppression of DRN 5-HT neurons during IS blocks IS-induced behavioral changes (Grahn, Maswood, McQueen, Watkins, \& Maier, 1999; Maier, Grahn, \& Watkins, 1995; Sutton, Grahn, Wiertelak, Watkins, \& Maier, 1997), and pharmacological activation of these neurons produces IS-like behavioral changes in the absence of shock (Hammack et al., 2002; Hammack, Pepin, et al., 2003; Hammack, Schmid, et al., 2003; Maier, Busch, Maswood, Grahn, \& Watkins, 1995). Together, these data suggest that IS produces a larger activation and release of caudal DRN 5-HT than does ES, and that this activation is responsible for the behavioral changes produced by uncontrollable shock. This hypothesis has been extensively reviewed (Maier \& Watkins, 1998) and may involve an interaction with LC NE systems (Grahn et al., 2002).

Low doses of CRH are inhibitory on DRN 5-HT neurons, but that inhibition subsides and becomes excitatory at high doses (Hammack, Pepin, DesMarteau, Watkins, \& Maier, 2003; Kirby, Rice, \& Valentino, 2000; Price, Curtis, Kirby, Valentino, \& Lucki, 1998; Price \& Lucki, 2001). Moreover, CRH excitation of DRN 5-HT neurons may be regionally selective, activating 5-HT neurons in the same caudal DRN area that is selectively activated by IS (Lowry, Rodda, Lightman, \& Ingram, 2000). Therefore, we have recently suggested that the caudal DRN 5-HT activation observed during IS is produced by the release of a CRH-like ligand into the caudal DRN during IS because (a) CRH activates caudal DRN neurons (Lowry, Rodda, Lightman, \& Ingram, 2000), (b) a DRN CRH antagonist blocks IS-induced behavioral changes, and (c) $\mathrm{CRH}$ produces the changes in the absence of shock (Hammack et al., 2002). Moreover, these effects are mediated by CRH Type 2 receptors (Hammack, Schmid, et al., 2003). The source of DRN $\mathrm{CRH}$ is unknown. As noted earlier, the extended amygdala is a major source of extrahypothalamic $\mathrm{CRH}$, and this is most notable for the BNST and the CeA (Gray \& Magnuson, 1992; Shimada et al., 1989; Swanson et al., 1983). As already noted, large electrolytic lesions of the amygdala that include the CeA do not block the behavioral changes induced by IS (Maier et al., 1993). Therefore, the BNST may be a likely region to modulate DRN activity, especially given its putative role in mediating long-duration responses to unpredictable stressors.

Because neurons in the caudal DRN mediate both the increased fear and decreased fight-flight associated with IS (Hammack et al., 2002; Maier et al., 1993), areas afferent to the DRN that drive its activity during IS should modulate both fear behavior and fightflight. Hence, if the BNST is an afferent source of CRH to the DRN, BNST lesion would be expected to attenuate the effects of IS on both fear behavior and behavior in an escape task. It has been suggested that DRN 5-HT facilitates learned defensive behaviors via forebrain projections, while simultaneously inhibiting fight-orflight reactions via projections to the dorsal periaqueductal gray (for a review, see Graeff, Viana, \& Mora, 1997). Furthermore Handley (1995) has suggested that 5-HT effects in active organisms tend toward behavioral inhibition. The data presented here support the notion that the BNST is involved in the shift from active fight-flight responding to passive behavioral inhibition, presumably through interactions with the DRN.

\section{References}

Amat, J., Matus-Amat, P., Watkins, L. R., \& Maier, S. F. (1998a). Escapable and inescapable stress differentially alter extracellular levels of 5-HT in the basolateral amygdala of the rat. Brain Research, 812, $113-120$.

Amat, J., Matus-Amat, P., Watkins, L. R., \& Maier, S. F. (1998b). Escapable and inescapable stress differentially and selectively alter extracellular levels of 5-HT in the ventral hippocampus and dorsal periaqueductal gray of the rat. Brain Research, 797, 12-22.

Aston-Jones, G., Delfs, J. M., Druhan, J., \& Zhu, Y. (1999). The bed nucleus of the stria terminalis: A target site for noradrenergic actions in opiate withdrawal. In J. F. McGinty (Ed.), Annals of the New York Academy of Sciences: Vol. 877. Advancing from the ventral striatum to the extended amygdala: Implications for neuropsychiatry and drug abuse (pp. 486-498). New York: New York Academy of Sciences.

Bland, S. T., Hargrave, D., Pepin, J. L., Amat, J., Watkins, L. R., \& Maier, S. F. (2003). Stressor controllability modulates stress-induced dopamine and serotonin efflux and morphine-induced serotonin efflux in the medial prefrontal cortex. Neuropsychopharmacology, 28, 1589-1598.

Casada, J. H., \& Dafny, N. (1991). Restraint and stimulation of bed nucleus of the stria terminalis produce similar stress-like behaviors. Brain Research Bulletin, 27, 207-212.

Casada, J. H., \& Dafny, N. (1993). Responses of neurons in bed nucleus of the stria terminalis to microiontophoretically applied morphine, norepinephrine and acetylcholine. Neuropharmacology, 32, 279-284.

Cecchi, M., Khoshbouei, H., Javors, M., \& Morilak, D. A. (2002). Mod- 
ulatory effects of norepinephrine in the lateral bed nucleus of the stria terminalis on behavioral and neuroendocrine responses to acute stress. Neuroscience, 112, 13-21.

Chappell, P. B., Smith, M. A., Kilts, C. D., Bissette, G., Ritchie, J., Anderson, C., \& Nemeroff, C. B. (1986). Alterations in corticotropinreleasing factor-like immunoreactivity in discrete rat brain regions after acute and chronic stress. Journal of Neuroscience, 6, 2908-2914.

Curtis, A. L., Bello, N. T., Connolly, K. R., \& Valentino, R. J. (2002). Corticotropin-releasing factor neurones of the central nucleus of the amygdala mediate locus coeruleus activation by cardiovascular stress. Journal of Neuroendocrinology, 14, 667-682.

Davis, M., Walker, D. L., \& Lee, Y. (1997). Roles of the amygdala and bed nucleus of the stria terminalis in fear and anxiety measured with the acoustic startle reflex: Possible relevance to PTSD. In Annals of the New York Academy of Sciences: Vol. 821. Psychobiology of posttraumatic stress disorder (pp. 305-331). New York: New York Academy of Sciences.

Delfs, J. M., Zhu, Y., Druhan, J. P., \& Aston-Jones, G. (2000, January). Noradrenaline in the ventral forebrain is critical for opiate withdrawalinduced aversion. Nature, 403, 430-434.

Dong, H. W., Petrovich, G. D., \& Swanson, L. W. (2001). Topography of projections from amygdala to bed nuclei of the stria terminalis. Brain Research Reviews, 38, 192-246.

Dong, H. W., Petrovich, G. D., Watts, A. G., \& Swanson, L. W. (2001). Basic organization of projections from the oval and fusiform nuclei of the bed nuclei of the stria terminalis in adult rat brain. Journal of Comparative Neurology, 436, 430-455.

Drugan, R. C., Skolnick, P., Paul, S. M., \& Crawley, J. N. (1989). A pretest procedure reliably predicts performance in two animal models of inescapable stress. Pharmacology Biochemistry and Behavior, 33, 649-654.

Dunn, J. D. (1987). Plasma corticosterone responses to electrical stimulation of the bed nucleus of the stria terminalis. Brain Research, 407, 327-331.

Fanselow, M., \& Lester, L. (1988). A functional behavioristic approach to aversively motivated behavior: Predatory imminence as a determinant of the topography of defensive behavior. In R. C. Bolles \& M. D. Beecher (Eds.), Evolution and learning (pp. 185-212). Hillsdale, NJ: Erlbaum.

Fendt, M., Endres, T., \& Apfelbach, R. (2003). Temporary inactivation of the bed nucleus of the stria terminalis but not of the amygdala blocks freezing induced by trimethylthiazoline, a component of fox feces. Journal of Neuroscience, 23, 23-28.

Gewirtz, J. C., McNish, K. A., \& Davis, M. (1998). Lesions of the bed nucleus of the stria terminalis block sensitization of the acoustic startle reflex produced by repeated stress, but not fear-potentiated startle. Progress in Neuro-psychopharmacology \& Biological Psychiatry, 22(4), 625-648.

Graeff, F. G., Viana, M. B., \& Mora, P. O. (1997). Dual Role of 5-HT in defense and anxiety. Neuroscience \& Biobehavioral Reviews, 21(6), 791-799.

Grahn, R. E., Hammack, S. E., Will, M. J., O’Connor, K. A., Deak, T., Sparks, P. D., et al. (2002). Blockade of alpha1 adrenoreceptors in the dorsal raphe nucleus prevents enhanced conditioned fear and impaired escape performance following uncontrollable stressor exposure in rats. Behavioural Brain Research, 134, 387-392.

Grahn, R. E., Maswood, S., McQueen, M. B., Watkins, L. R., \& Maier, S. F. (1999). Opioid-dependent effects of inescapable shock on escape behavior and conditioned fear responding are mediated by the dorsal raphe nucleus. Behavioural Brain Research, 99, 153-167.

Grahn, R. E., Will, M. J., Hammack, S. E., Maswood, S., McQueen, M. B., Watkins, L. R., \& Maier, S. F. (1999). Activation of serotoninimmunoreactive cells in the dorsal raphe nucleus in rats exposed to an uncontrollable stressor. Brain Research, 826, 35-43.

Gray, T. S., \& Magnuson, D. J. (1992). Peptide immunoreactive neurons in the amygdala and the bed nucleus of the stria terminalis project to the midbrain central gray in the rat. Peptides, 13, 451-460.

Gray, T. S., Piechowski, R. A., Yracheta, J. M., Rittenhouse, P. A., Bethea, C. L., \& Van de Kar, L. D. (1993). Ibotenic acid lesions in the bed nucleus of the stria terminalis attenuate conditioned stress-induced increases in prolactin, ACTH and corticosterone. Neuroendocrinology, 57, 517-524.

Hammack, S. E., Pepin, J. L., DesMarteau, J. S., Watkins, L. R., \& Maier, S. F. (2003). Low doses of corticotropin-releasing hormone injected into the dorsal raphe nucleus block the behavioral consequences of uncontrollable stress. Behavioural Brain Research, 147, 55-64.

Hammack, S. E., Richey, K. J., Schmid, M. J., LoPresti, M. L., Watkins, L. R., \& Maier, S. F. (2002). The role of corticotropin-releasing hormone in the dorsal raphe nucleus in mediating the behavioral consequences of uncontrollable stress. Journal of Neuroscience, 22, 1020-1026.

Hammack, S. E., Schmid, M. J., LoPresti, M. L., Der-Avakian, A., Pellymounter, M. A., Foster, A. C., et al. (2003). Corticotropin releasing hormone type 2 receptors in the dorsal raphe nucleus mediate the behavioral consequences of uncontrollable stress. Journal of Neuroscience, 23, 1019-1025.

Handley, S. L. (1995). 5-Hydroxytryptamine pathways in anxiety and its treatment. Pharmacology and Therapeutics, 66, 103-148.

Henke, P. G. (1984). The bed nucleus of the stria terminalis and immobilization-stress: Unit activity, escape behaviour, and gastric pathology in rats. Behavioural Brain Research, 11, 35-45.

Hitchcock, J. M., \& Davis, M. (1991). Efferent pathway of the amygdala involved in conditioned fear as measured with the fear-potentiated startle paradigm. Behavioral Neuroscience, 105, 826-842.

Kirby, L. G., Rice, K. C., \& Valentino, R. J. (2000). Effects of corticotropin-releasing factor on neuronal activity in the serotonergic dorsal raphe nucleus. Neuropsychopharmacology, 22, 148-162.

LeDoux, J. E., Iwata, J., Cicchetti, P., \& Reis, D. J. (1988). Different projections of the central amygdaloid nucleus mediate autonomic and behavioral correlates of conditioned fear. Journal of Neuroscience, 8 , 2517-2529.

Lee, Y., \& Davis, M. (1997). Role of the hippocampus, the bed nucleus of the stria terminalis, and the amygdala in the excitatory effect of corticotropin-releasing hormone on the acoustic startle reflex. Journal of Neuroscience, 17, 6434-6446.

Leri, F., Flores, J., Rodaros, D., \& Stewart, J. (2002). Blockade of stressinduced but not cocaine-induced reinstatement by infusion of noradrenergic antagonists into the bed nucleus of the stria terminalis or the central nucleus of the amygdala. Journal of Neuroscience, 22, 5713-5718.

Lowry, C. A., Rodda, J. E., Lightman, S. L., \& Ingram, C. D. (2000). Corticotropin-releasing factor increases in vitro firing rates of serotonergic neurons in the rat dorsal raphe nucleus: Evidence for activation of a topographically organized mesolimbocortical serotonergic system. Journal of Neuroscience, 20, 7728-7736.

MacLean, P. D. (1985). Fiber systems of the forebrain. In G. Paxinos (Ed.), The rat nervous system (Vol. 1, pp. 417-440). Orlando, FL: Academic Press.

Maier, S. F. (1990). Role of fear in mediating shuttle escape learning deficit produced by inescapable shock. Journal of Experimental Psychology: Animal Behavior Processes, 16, 137-149.

Maier, S. F., Busch, C. R., Maswood, S., Grahn, R. E., \& Watkins, L. R. (1995). The dorsal raphe nucleus is a site of action mediating the behavioral effects of the benzodiazepine receptor inverse agonist DMCM. Behavioral Neuroscience, 109, 759-766.

Maier, S. F., Grahn, R. E., Kalman, B. A., Sutton, L. C., Wiertelak, E. P., \& Watkins, L. R. (1993). The role of the amygdala and dorsal raphe nucleus in mediating the behavioral consequences of inescapable shock. Behavioral Neuroscience, 107, 377-388.

Maier, S. F., Grahn, R. E., \& Watkins, L. R. (1995). 8-OH-DPAT microinjected in the region of the dorsal raphe nucleus blocks and reverses the 
enhancement of fear conditioning and interference with escape produced by exposure to inescapable shock. Behavioral Neuroscience, 109, 404412

Maier, S. F., \& Seligman, M. E. P. (1976). Learned helplessness: Theory and evidence. Journal of Experimental Psychology: General, 105, 3-46.

Maier, S. F., \& Watkins, L. R. (1998). Stressor controllability, anxiety and serotonin. Cognitive Therapy and Research, 22, 595-613.

Makino, S., Shibasaki, T., Yamauchi, N., Nishioka, T., Mimoto, T., Wakabayashi, I., et al. (1999). Psychological stress increased corticotropinreleasing hormone mRNA and content in the central nucleus of the amygdala but not in the hypothalamic paraventricular nucleus in the rat. Brain Research, 850, 136-143.

Maswood, S., Barter, J. E., Watkins, L. R., \& Maier, S. F. (1998). Exposure to inescapable but not escapable shock increases extracellular levels of 5-HT in the dorsal raphe nucleus of the rat. Brain Research, 783, $115-120$.

McDonald, A. J., Shammah-Lagnado, S. J., Shi, C., \& Davis, M. (1999). Cortical afferents to the extended amygdala. In J. F. McGinty (Ed.), Annals of the New York Academy of Sciences: Vol. 877. Advancing from the ventral striatum to the extended amygdala: Implications for neuropsychiatry and drug abuse (pp. 309-338). New York: New York Academy of Sciences.

Moga, M. M., Saper, C. B., \& Gray, T. S. (1989). Bed nucleus of the stria terminalis: Cytoarchitecture, immunohistochemistry, and projection to the parabrachial nucleus in the rat. Journal of Comparative Neurology, 283, 315-332.

Onaka, T., \& Yagi, K. (1998). Role of noradrenergic projections to the bed nucleus of the stria terminalis in neuroendocrine and behavioral responses to fear-related stimuli in rats. Brain Research, 788, 287-293.

Pacak, K., McCarty, R., Palkovits, M., Kopin, I. J., \& Goldstein, D. S. (1995). Effects of immobilization on in vivo release of norepinephrine in the bed nucleus of the stria terminalis in conscious rats. Brain Research, 688, 242-246.

Paxinos, G., \& Watson, C. (1998). The rat brain in stereotaxic coordinates (4th ed.). San Diego, CA: Academic Press.

Phelix, C. F., \& Paull, W. K. (1990). Demonstration of distinct corticotropin releasing factor-containing neuron populations in the bed nucleus of the stria terminalis. A light and electron microscopic immunocytochemical study in the rat. Histochemistry, 94, 345-364.

Price, M. L., Curtis, A. L., Kirby, L. G., Valentino, R. J., \& Lucki, I. (1998). Effects of corticotropin-releasing factor on brain serotonergic activity. Neuropsychopharmacology, 18, 492-502.

Price, M. L., \& Lucki, I. (2001). Regulation of serotonin release in the lateral septum and striatum by corticotropin-releasing factor. Journal of Neuroscience, 21, 2833-2841.

Schulz, D., \& Canbeyli, R. (1999). Freezing behavior in BNST-lesioned Wistar rats. In J. F. McGinty (Ed.), Annals of the New York Academy of Sciences: Vol. 877. Advancing from the ventral striatum to the extended amygdala: Implications for neuropsychiatry and drug abuse (pp. 728 731). New York: New York Academy of Sciences.
Schulz, D., \& Canbeyli, R. S. (2000). Lesion of the bed nucleus of the stria terminalis enhances learned despair. Brain Research Bulletin, 52, 8387.

Shimada, S., Inagaki, S., Kubota, Y., Ogawa, N., Shibasaki, T., \& Takagi, H. (1989). Coexistence of peptides (corticotropin releasing factor/neurotensin and substance P/somatostatin) in the bed nucleus of the stria terminalis and central amygdaloid nucleus of the rat. Neuroscience, 30, 377-383.

Shumake, J., Edwards, E., \& Gonzalez-Lima, F. (2002). Dissociation of septo-hippocampal metabolism in the congenitally helpless rat. Neuroscience, 114, 373-377.

Stout, S. C., Mortas, P., Owens, M. J., Nemeroff, C. B., \& Moreau, J. (2000). Increased corticotropin-releasing factor concentrations in the bed nucleus of the stria terminalis of anhedonic rats. European Journal of Pharmacology, 401, 39-46.

Sutton, L. C., Grahn, R. E., Wiertelak, E. P., Watkins, L. R., \& Maier, S. F. (1997). Inescapable shock-induced potentiation of morphine analgesia in rats: Involvement of opioid, GABAergic, and serotonergic mechanisms in the dorsal raphe nucleus. Behavioral Neuroscience, 111, 816-824.

Swanson, L. W., Sawchenko, P. E., Rivier, J., \& Vale, W. W. (1983). Organization of ovine corticotropin-releasing factor immunoreactive cells and fibers in the rat brain: An immunohistochemical study. Neuroendocrinology, 36, 165-186.

Treit, D., Aujla, H., \& Menard, J. (1998). Does the bed nucleus of the stria terminalis mediate fear behaviors? Behavioral Neuroscience, 112, 379386.

Van Bockstaele, E. J., Peoples, J., \& Valentino, R. J. (1999). A. E. Bennett Research Award. Anatomic basis for differential regulation of the rostrolateral peri-locus coeruleus region by limbic afferents. Biological Psychiatry, 46, 1352-1363.

Walker, D. L., \& Davis, M. (1997). Double dissociation between the involvement of the bed nucleus of the stria terminalis and the central nucleus of the amygdala in startle increases produced by conditioned versus unconditioned fear. Journal of Neuroscience, 17, 9375-9383.

Walker, D. L., Toufexis, D. J., \& Davis, M. (2003). Role of the bed nucleus of the stria terminalis versus the amygdala in fear, stress, and anxiety. European Journal of Pharmacology, 463(1-3), 199-216.

Weiss, J. M., Goodman, P. A., Losito, B. A., Corrigan, S., Charry, J. M., \& Bailey, W. H. (1981). Behavioral depression produced by an uncontrollable stressor: Relationship to norepinephrine, dopamine, and serotonin levels in various regions of rat brain. Brain Research Reviews, 3, 167-205.

Weiss, J. M., \& Simson, P. G. (1985). Neurochemical mechanisms underlying stress-induced depression. In T. M. Field, P. M. McCabe, \& N. Schneiderman (Eds.), Stress and coping (pp. 93-116). Hillsdale, NJ: Erlbaum.

Received July 17, 2003

Revision received September 4, 2003

Accepted September 30, 2003 